\title{
EFFECTS OF MEDIAL AND LATERAL WEDGED ORTHOSES ON KNEE AND ANKLE JOINT LOADING IN FEMALE RUNNERS
}

\author{
Jonathan Sinclair and Philip Stainton \\ Faculty of Health \& Wellbeing, University of Central Lancashire, United Kingdom
}

Original scientific article

DOI: $10.26582 / \mathrm{k} .51 .2 .9$

\begin{abstract}
:
The aim of the current investigation was to examine the effects of orthoses with a $5^{\circ}$ medial and lateral wedge on knee and ankle joint kinetics in female runners. Twelve healthy female runners ran at $3.5 \mathrm{~m} / \mathrm{s}$ over a force platform in three conditions (medial, lateral and no-orthotic). Lower extremity kinematics were measured using an 8-camera motion capture system, which allowed knee and ankle loading to be explored using a musculoskeletal modelling approach. The peak Achilles tendon force was significantly larger in the no-orthotic condition (5.34 BW) compared to the lateral orthosis (5.03 BW). The peak patellofemoral stress was significantly larger in the medial orthosis $(7.32 \mathrm{MPa})$ compared to the no-orthotic (7.02 MPa) condition. Finally, the peak knee adduction moment was significantly larger in the medial condition (1.14 $\mathrm{Nm} / \mathrm{kg})$ compared to the lateral $(0.99 \mathrm{Nm} / \mathrm{kg})$ orthosis. The findings from the current investigation indicate that lateral orthoses may be effective in attenuating risk of medial tibiofemoral osteoarthritis and Achilles tendinopathy, but medial wedge orthoses may increase the risk of patellofemoral pain in female runners.
\end{abstract}

Key words: biomechanics, orthoses, kinetics, running

\section{Introduction}

Running is linked to a high incidence of overuse injuries ( Hreljac, 2004; Taunton, et al., 2002), with an occurrence rate of up to $70 \%$ per year (Van Gent, et al., 2007). The knee and ankle joints have been demonstrated as the most commonly injured musculoskeletal sites (van Gent, et al., 2007). Importantly female runners are renowned for being at an increased risk of chronic injuries in relation to males (Taunton, et al., 2002).

Patellofemoral pain is the most common chronic injury encountered in sports medicine (Crossley, 2014), characterized by pain at or anterior to the patella exacerbated by cyclic physical activities such as running that frequently load the patellofemoral joint (Crossley, et al., 2016). Pain symptoms typically persist for many years (Collins, et al., 2013), and force many runners to mediate or even cease their training (Waryasz \& McDermott, 2008). The peak patellofemoral joint stress, a manifestation of the patellofemoral joint reaction force divided by the patellofemoral contact area, is widely regarded as the most prominent biomechanical mechanism linked to the aetiology of patellofemoral pain syndrome (Farrokhi, Keyak, \& Powers 2011). Importantly, a recent systematic review has shown that there may be a link between patellofemoral pain in younger adults and subsequent osteoarthritis (OA) at this joint (Thomas, Wood, Selfe, $\&$ Peat 2013).
Furthermore, chronic tibiofemoral pathologies are also common running injuries, associated with up to $16.8 \%$ of all knee injuries (Taunton, et al., 2002). The medial aspect of the knee is significantly more susceptible to injury than the lateral compartment (Wise, et al., 2012). In vivo analyses have shown that compressive loading experienced by the medial aspect of the tibiofemoral joint is correlated positively with the magnitude of the knee adduction moment (KAM) (Kutzner, Trepczynski, Heller, Bergmann 2013; Zhao, et al., 2007). Therefore, the KAM is frequently utilized as a pseudo measure of medial tibiofmeoral contact loading (Birmingham, Hunt, Jones, Jenkyn, \& Giffin 2007), and the peak KAM has been cited as an important predictor of radiographic knee OA (Miyazaki, et al., 2002; Morgenroth, Medverd, Seyedali, \& Czerniecki 2014).

Finally, Achilles tendinopathies are also frequently occurring chronic musculoskeletal disorders in runners, accounting for approximately $8-15 \%$ of all injuries (Van Ginckel, et al., 2009). Although the Achilles tendon is regarded as the strongest tendon in the body, it is the most common site of tendinous injury (Rice \& Patel, 2017). During running, the Achilles tendon experiences forces up to 7 BW (Almonroeder, Willson, \& Kernozek 2013). Excessive cyclic forces experienced by the tendon during activities such as running are regarded as the main pathological stimulus for the initiation of 
Achilles tendinopathy (Abate, et al., 2009). With repeated high and insufficient time for repair, the reparative capability of the tendon is exceeded breaking the cross-links and causing degeneration of the tendon's collagen fibrils (Cook \& Purdam, 2009).

Taking into account the high incidence of running injuries, and the debilitating nature of chronic pathologies, a range of preventative mechanisms have been explored in biomechanical literature in order to attenuate the risk of injury in runners. Foot orthoses are one of the most commonly utilized modalities for the prevention/treatment of running injuries (Bonanno, Landorf, Munteanu, Murley, \& Menz 2017). Foot orthoses are available in both medial and lateral configurations, which are utilized in order to specifically modify the alignment of the lower extremities and redistribute the loads experienced at the lower body joints (Liu \& Zhang, 2013). The effects of medial/lateral orthoses on the biomechanics of the lower extremities have been examined previously; however, they have habitually been examined during walking in pathological patients (Pham, et al., 2004; Rubin \& Menz, 2005; Baker, et al, 2007; Barrios \& Davis, 2010; Bennell, et al., 2010; Rafiaee \& Karimi, 2012; Barrios, Butler, Crenshaw, Royer, \& Davis, 2013) and there is only limited information concerning their effects during running.

Boldt et al. (2013) examined the effects of $6^{\circ}$ medially wedged orthoses on the biomechanics of the hip and knee joint in female runners with and without patellofemoral pain. Their findings showed in both groups that the peak KAM increased, and the hip adduction excursion decreased when wearing the medial orthoses. Almonroeder et al. (2015) examined the effects of prefabricated foot orthoses with $5^{\circ}$ of medial wedging in female runners. Medial orthoses significantly increased peak patellofemoral stress in comparison to running without orthoses. Lewinson et al. (2013), who explored the influence of 3,6, and $9 \mathrm{~mm}$ medial and lateral wedged footwear on the KAM in males, showed that the laterally wedged running footwear were associated with significant reductions in the peak KAM. Sinclair (2018) studied the effects of $5^{\circ}$ medial and lateral orthoses on the knee joint loading in male runners. Their findings showed that patellofemoral loading was significantly increased in the medial and lateral orthoses compared to no-orthoses, and the peak KAM was significantly increased in the medial compared to the lateral orthoses. Nigg et al. (2003) examined the effects of medial, lateral and neutral shoe inserts on the knee joint moments during heeltoe running in males. Compared with the neutral insert condition, the maximal external knee rotation moment was found to be significantly greater in the medial insert condition. Starbuck, Price, Smith, \& Jones, (2017) examined the effects of an off-theshelf lateral wedge orthotic on the knee loading in a mixed sample of runners. Their results showed that the orthoses did not statistically influence the knee loading parameters during the stance phase. Using an in-vitro analysis, Kogler, Veer, Solomonidis, and Paul (1999) investigated the influence of medial and lateral orthotic wedges on the loading of the plantar aponeurosis. Their findings showed that wedging under the lateral aspect of the forefoot decreased strain in the plantar aponeurosis, but medial wedges increased plantar aponeurosis strain.

However, whilst the effects of foot orthoses on the biomechanics of the knee joint during gait have been examined previously, there has yet to be an investigation that would collectively explore the effects of medial and lateral orthoses on patellofemoral, tibiofemoral and Achilles tendon kinetics in female runners. Therefore, the aim of the current investigation was to examine the effects of orthoses with a $5^{\circ}$ medial and lateral wedge on patellofemoral, Achilles tendon and KAM loading parameters during stance phase in female runners. A clinical investigation of this nature may provide insight into the potential efficacy of wedged foot orthoses for the prevention of knee and ankle pathologies in female runners.

\section{Methods}

\section{Participants}

Twelve healthy female recreational runners, who trained at least three times/week over a minimum distance of $35 \mathrm{~km}$ (age $28.75 \pm 6.69$ years, body height $1.62 \pm 0.06 \mathrm{~m}$ and body mass 62.21 $\pm 3.31 \mathrm{~kg}$ ) volunteered to take part in this study. Each runner exhibited a rearfoot strike pattern as they exhibited an impact peak in their vertical ground reaction force curve. Participants were free from knee and ankle pathology at the time of data collection and had not previously had any knee or ankle surgery. The participants provided written informed consents and the procedure was approved by the University's ethical panel (REF 357). The runners did not habitually utilize orthoses during their training activities.

\section{Orthoses}

Commercially available orthoses (Slimflex Simple, Algeos, UK) made from ethylene-vinyl acetate with a shore A rating of 65 were examined (Sinclair, 2018). The orthoses were modifiable, allowing either a $5^{\circ}$ varus or valgus configuration spanning the full length of the device (Figure 1). To ensure consistency, each participant wore the same footwear (Asics, Patriot 6) (Figure 2). The experimental footwear had a mean mass of $0.265 \mathrm{~kg}$, heel thickness of $22 \mathrm{~mm}$ and heel drop of $10 \mathrm{~mm}$. To prevent any order effects on the experimental data, participants ran in each orthotic condition in a counterbalanced manner. This was achieved by 
giving each orthotic condition a letter either $\mathrm{A}, \mathrm{B}$ or $\mathrm{C}$, and presenting the orthoses in each of the six available sequences (ABC, $\mathrm{ACB}, \mathrm{BAC}, \mathrm{BCA}, \mathrm{CAB}$, and $\mathrm{CBA}$ ) to the first six participants, then repeating the process for the second six.
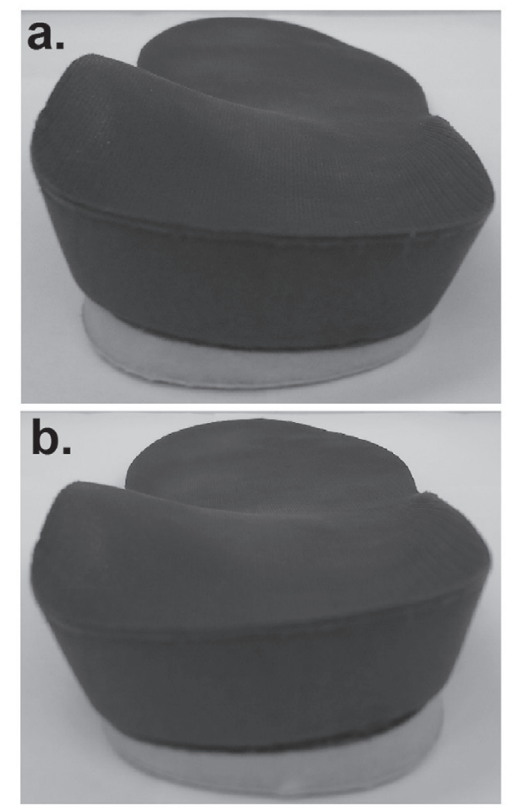

Figure 1. Experimental orthoses (a. = medial configuration and $b .=$ lateral configuration).

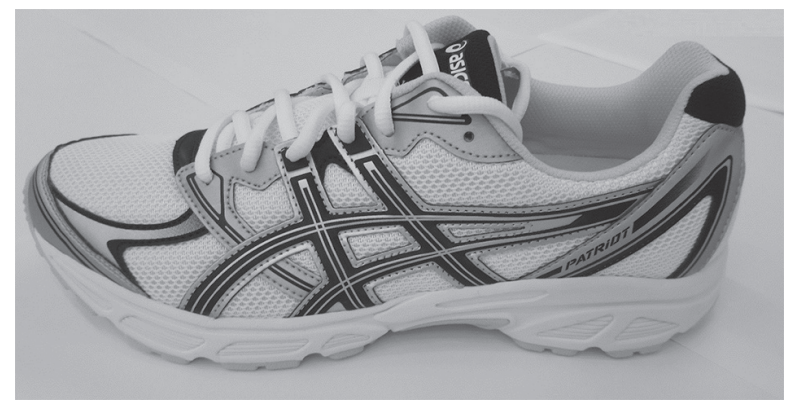

Figure 2. Experimental footwear.

\section{Procedure}

Participants ran over-ground at $3.5 \mathrm{~m} / \mathrm{s}$ (Fukuchi, Fukuchi, \& Duarte, 2017), in three conditions (medial, lateral and no-orthotic), striking a piezoelectric force platform (Kistler, Kistler Instruments Ltd.), sampling at $1000 \mathrm{~Hz}$, with their right (dominant) foot. Limb dominance was determined by asking participants which foot they would utilize to kick a ball. Running velocity was monitored using infrared timing gates (Newtest, Oy, Finland) and a maximum deviation from the experimental running velocity was allowed. To ensure that a constant running velocity was measured with no evidence of targeting the force platform, the anterior-posterior ground reaction force was qualitatively examined following each trial, and the running trials were inspected visually for evidence of modification to the stride pattern. The stance phase was delineated as the duration over which $>20 \mathrm{~N}$ vertical force was applied to the force platform. Runners completed five successful trials in each orthotic condition. Kinematic data was captured at $250 \mathrm{~Hz}$ via an eightcamera motion capture system (Qualisys Medical AB, Gothenburg, Sweden).

Lower extremity segments were modelled in six degrees of freedom using the calibrated anatomical systems technique (Cappozzo, Catani, Leardini, Benedeti, \& Della, 1995). To define the segment co-ordinate axes of the right foot, shank and thigh, retroreflective markers were placed unilaterally onto the 1st metatarsal, 5th metatarsal, calcaneus, medial and lateral malleoli, medial and lateral epicondyles of the femur. To define the pelvis segment, further markers were positioned onto the anterior (ASIS) and posterior (PSIS) superior iliac spines. The centres of the ankle and knee joints were delineated as the mid-point between the malleoli and femoral epicondyle markers (Graydon, Fewtrell, Atkins, \& Sinclair 2015; Sinclair, Hebron, \& Taylor, 2015), whereas the hip joint centre was obtained using the positions of the ASIS markers (Sinclair, Taylor, Currigan, \& Hobbs, 2014a). The Z (transverse) axis was oriented vertically from the distal segment end to the proximal segment end. The $\mathrm{Y}$ (coronal) axis was oriented in the segment from posterior to anterior. Finally, the $\mathrm{X}$ (sagittal) axis orientation was determined using the right-hand rule and was oriented from medial to lateral. To track the shank and thigh segments, carbon fiber tracking clusters, comprising four non-linear retroreflective markers, were positioned onto these segments. Furthermore, the foot was tracked using the 1st metatarsal, 5th metatarsal and calcaneus markers and the pelvis using the ASIS and PSIS markers. Following marker placement, static calibration trials (not normalized to static trial posture) were obtained in each orthotic condition allowing for the anatomical markers to be referenced in relation to the tracking markers/clusters.

\section{Processing}

Dynamic trials were digitized using Qualisys Track Manager then exported as C3D files to Visual 3D (C-Motion, Germantown, USA). The ground reaction force and kinematic data were smoothed using cut-off frequencies of 50 and $12 \mathrm{~Hz}$ with a lowpass Butterworth $4^{\text {th }}$ order zero-lag filter (Sinclair, 2018). Knee loading was examined through extraction of the peak KAM, peak patellofemoral contact force and contact stress, whereas ankle loading was explored by extracting the peak Achilles tendon force.

Patellofemoral force and stress were estimated using the model of Ward and Powers (2004). This model has been shown to be sufficiently sensitive to resolve the differences in patellofemoral loading between sexes (Sinclair \& Selfe, 2015) and orthoses 
(Sinclair, 2018). Input parameters into the model were knee flexion angle, quadriceps moment arm, quadriceps force and knee extensor moment (Ho, Blanchette, \& Powers 2012; van Eijden, Kouwenhoven, Verburg, \& Weijs 1986):

Firstly, an effective moment arm of the quadriceps muscle was quantified:

\section{Quadriceps moment arm $=0.00008$ * knee flexion angle ${ }^{3}-0.013 *$ knee flexion angle ${ }^{2}$ $+0.28 *$ knee flexion angle $+\mathbf{0 . 0 4 6}$}

Quadriceps force was then estimated using the formula below:

\section{Quadriceps force $=$ knee extensor moment / quadriceps moment arm}

Patellofemoral contact force was estimated using the quadriceps force and a constant:

\section{Patellofemoral contact force $=$ quadriceps force * constant}

The constant was described in relation to the knee flexion angle using a curve fitting technique based on the non-linear equation described by Eijden et al. (1986)

\section{Çonstant $=(0.462+0.00147 *$ knee flexion angle $^{2}-0.0000384 *$ knee flexion angle $\left.{ }^{2}\right) /$ $(1-0.0162 *$ knee flexion angle +0.000155$$
\text { * knee flexion angle }{ }^{2}-0.000000698 * \text { knee }
$$$$
\text { flexion angle }{ }^{3} \text { ) }
$$

Contact stress (MPa) was estimated as a function of the contact force divided by the sex specific patellofemoral contact areas as described by Besier, Draper, Gold, Beaupre, \& Delp (2005):

\section{Patellofemoral contact stress $=$ patellofemoral contact force / contact area}

Achilles tendon force was determined using the musculoskeletal model of Self and Paine (2001), which has been shown to be sufficiently sensitive to resolve the differences in Achilles tendon loading between sexes (Greenhalgh \& Sinclair, 2014) and orthoses (Sinclair, Isherwood, \& Taylor, 2014b). Input parameters into the model were ankle plantarflexion moment, ankle sagittal plane angle and Achilles tendon moment arm:

\section{Achilles tendon force $=$ ankle plantarflexion moment / Achilles tendon moment arm}

Achilles tendon moment arm $=\mathbf{- 0 . 5 9 1 0}$

$+0.08297 *$ ankle sagittal plane angle 0.0002606 * ankle sagittal plane angle ${ }^{2}$

Patellofemoral and Achilles tendon forces were normalized by dividing the net values by body weight (BW), whereas the KAM was normalized by dividing by body mass. The patellofemoral and Achilles tendon average load rates (BW/s) were quantified as the peak force divided by the time to peak force, whereas the instantaneous load rate (BW/s) was determined as the maximum increase in force between frequency intervals. The KAM average load rate $(\mathrm{Nm} / \mathrm{kg} / \mathrm{s})$ was quantified as the peak KAM divided by the time taken, whereas the instantaneous KAM load rate $(\mathrm{Nm} / \mathrm{kg} / \mathrm{s})$ was determined as the maximum increase between frequency intervals. The patellofemoral/Achilles tendon $(\mathrm{BW} \cdot \mathrm{s})$ and $\mathrm{KAM}(\mathrm{N} / \mathrm{kg} \cdot \mathrm{s})$ impulses were calculated by multiplying the load during the stance phase by the stance phase duration.

\section{Statistical analyses}

Means, standard deviations (SD) and 95\% confidence intervals $(95 \% \mathrm{CI})$ were calculated for each outcome measurement for all the three orthotic conditions. Differences between the orthotic conditions were examined using one-way repeated measures ANOVA. Effect sizes were calculated using partial eta ${ }^{2}\left(\mathrm{p}^{2}\right)$. Post-hoc pairwise comparisons were conducted on all the significant main effects. In the event of a post-hoc comparison indicating statistical significance, the number of participants (N) who followed the direction of the statistical difference was reported. Finally, the mean difference and $95 \%$ CI of the difference between the orthotic conditions for each outcome measurement were also calculated. Statistical actions were all conducted using SPSS v23.0 (SPSS, USA).

\section{Results}

Figure 3 and Tables 1 and 2 present knee and ankle kinetic parameters as a function of different orthotic conditions.

\section{Achilles tendon kinetics}

A main effect $\left(\mathrm{p}<.05, \mathrm{p} \eta^{2}=0.27\right)$ was evident for peak Achilles tendon force. Post-hoc analyses
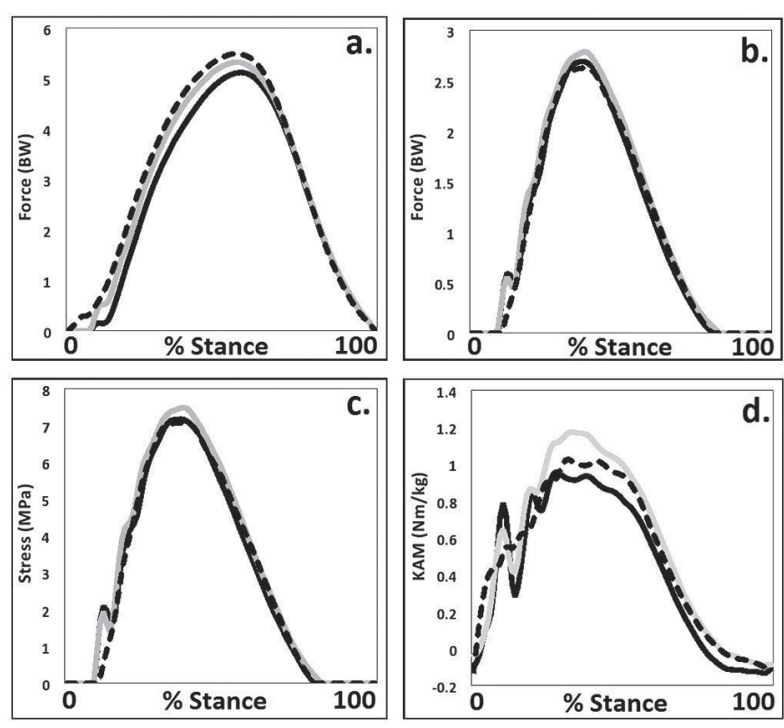

Figure 3. Knee and ankle kinetics as a function of different orthotic conditions ( $a .=$ Achilles tendon force, $b .=$ patellofemoral force, $c .=$ patellofemoral stress, $d .=K A M)$ (black line = lateral, dotted line = no-orthotic, grey line = medial). 
Table 1. Knee and ankle loading parameters (means, standard deviations and 95\% confidence intervals) as a function of the different orthotic conditions

\begin{tabular}{|c|c|c|c|c|c|c|c|c|c|c|}
\hline & \multicolumn{3}{|c|}{ Medial } & \multicolumn{3}{|c|}{ Lateral } & \multicolumn{4}{|c|}{ No-orthotic } \\
\hline & Mean & SD & $95 \% \mathrm{Cl}$ & Mean & SD & $95 \% \mathrm{Cl}$ & Mean & SD & $95 \% \mathrm{Cl}$ & \\
\hline Peak Achilles tendon force (BW) & 5.18 & 0.77 & $4.69-5.67$ & $5.03 \mathrm{~A}$ & 0.71 & $4.58-5.47$ & 5.34 & 0.85 & $4.80-5.88$ & \\
\hline Achilles tendon average load rate (BW/s) & 44.87 & 10.28 & $38.47-51.40$ & 43.39 & 8.48 & $38.00-48.78$ & 46.83 & 12.60 & $38.82-54.83$ & \\
\hline Achilles tendon instantaneous load rate (BW/s) & $190.74 A B$ & 83.92 & $137.42-244.06$ & 141.23 & 45.33 & $112.43-170.03$ & 138.55 & 43.49 & $110.92-166.18$ & * \\
\hline Achilles tendon impulse (BW.s) & 0.55 & 0.10 & $0.48-0.62$ & $0.52 A$ & 0.11 & $0.45-0.59$ & 0.58 & 0.11 & $0.51-0.65$ & " \\
\hline Peak patellofemoral force (BW) & $2.77 A B$ & 0.74 & $2.30-3.24$ & 2.62 & 0.80 & $2.11-3.12$ & 2.60 & 0.76 & $2.11-3.08$ & * \\
\hline Patellofemoral average load rate (BW/s) & 23.85 & 7.32 & $19.21-28.50$ & 22.25 & 7.03 & $17.78-26.71$ & 22.53 & 7.71 & $17.63-27.43$ & \\
\hline Patellofemoral instantaneous load rate (BW/s) & 172.67 B & 63.59 & $132.27-213.08$ & $159.14 A$ & 75.00 & $111.49-206.79$ & 132.51 & 50.91 & $100.16-164.86$ & * \\
\hline Patellofemoral impulse (BW·s) & $0.22 B$ & 0.06 & $0.18-0.26$ & 0.19 & 0.08 & $0.14-0.24$ & 0.19 & 0.07 & $0.15-0.24$ & \\
\hline Peak patellofemoral stress (MPa) & $7.37 \mathrm{~A}$ & 1.86 & $6.19-8.56$ & 7.13 & 2.07 & $5.82-8.45$ & 7.02 & 1.88 & $5.83-8.22$ & * \\
\hline Peak KAM (Nm/kg) & $1.14 B$ & 0.49 & $0.83-1.45$ & 0.99 & 0.34 & $0.78-1.21$ & 1.06 & 0.38 & $0.82-1.31$ & * \\
\hline KAM average load rate $(\mathrm{Nm} / \mathrm{kg} / \mathrm{s})$ & 32.84 & 28.94 & $14.46-51.23$ & 28.34 & 20.90 & $15.06-41.62$ & 27.76 & 17.97 & $16.35-39.18$ & \\
\hline KAM instantaneous load rate $(\mathrm{Nm} / \mathrm{kg} / \mathrm{s})$ & 100.61 & 60.05 & $62.46-138.77$ & 93.36 & 45.87 & $64.21-122.50$ & 94.20 & 45.50 & $65.29-123.11$ & \\
\hline KAM impulse (Nm/kg·s) & $0.08 B$ & 0.05 & $0.05-0.11$ & $0.06 \mathrm{~A}$ & 0.04 & $0.04-0.09$ & 0.08 & 0.04 & $0.06-0.11$ & \\
\hline
\end{tabular}

Note. ${ }^{*}=$ significant main effect; $A=$ significantly different from no-orthotic; $B=$ significantly different from lateral orthotic.

Table 2. Mean and 95\% confidence interval differences between experimental conditions

\begin{tabular}{|c|c|c|c|c|c|c|}
\hline & \multicolumn{2}{|c|}{ Medial vs. lateral } & \multicolumn{2}{|c|}{ Medial vs. no-orthotic } & \multicolumn{2}{|c|}{ Lateral vs. no-orthotic } \\
\hline & $\begin{array}{c}\text { Mean } \\
\text { difference }\end{array}$ & $\begin{array}{c}95 \% \mathrm{Cl} \\
\text { difference }\end{array}$ & $\begin{array}{c}\text { Mean } \\
\text { difference }\end{array}$ & $\begin{array}{c}95 \% \mathrm{Cl} \\
\text { difference }\end{array}$ & $\begin{array}{c}\text { Mean } \\
\text { difference }\end{array}$ & $\begin{array}{c}95 \% \mathrm{Cl} \\
\text { difference }\end{array}$ \\
\hline Peak Achilles tendon force (BW) & 0.15 & $-0.16-0.46$ & -0.16 & $-0.34-0.03$ & -0.31 & $-0.60--0.02$ \\
\hline Achilles tendon average load rate (BW/s) & 1.48 & $-2.22-5.18$ & -1.95 & $-5.60-1.69$ & -3.43 & $-8.33-1.46$ \\
\hline Achilles tendon instantaneous load rate (BW/s) & 49.52 & $21.03-78.00$ & 52.19 & $5.58-98.80$ & 2.68 & $-21.73-27.08$ \\
\hline Achilles tendon impulse (BW·s) & 0.03 & $-0.02-0.09$ & -0.03 & $-0.07-0.01$ & -0.06 & $-0.10--0.02$ \\
\hline Peak patellofemoral force (BW) & 0.15 & $0.05-0.26$ & 0.17 & $0.02-0.31$ & 0.02 & $-0.16-0.19$ \\
\hline Patellofemoral average load rate (BW/s) & 1.61 & $-0.05-2.64$ & 1.32 & $-0.32-2.97$ & -0.28 & $-1.51-0.95$ \\
\hline Patellofemoral instantaneous load rate (BW/s) & 13.53 & $-4.44-31.50$ & 40.16 & $25.10-55.23$ & 26.63 & $3.59-49.67$ \\
\hline Patellofemoral impulse (BW·s) & 0.02 & $0.01-0.04$ & 0.02 & $-0.01-0.05$ & -0.001 & $-0.03-0.03$ \\
\hline Peak patellofemoral stress (MPa) & 0.24 & $-0.07-0.55$ & 0.35 & $0.01-0.69$ & 0.11 & $-0.36-0.58$ \\
\hline Peak KAM (Nm/kg) & 0.15 & $0.003-0.29$ & 0.07 & $-0.10-0.25$ & -0.07 & $-0.18-0.03$ \\
\hline KAM average load rate $(\mathrm{Nm} / \mathrm{kg} / \mathrm{s})$ & 4.50 & $-5.98-14.99$ & 5.08 & $-9.50-19.65$ & 0.58 & $-7.09-8.25$ \\
\hline KAM instantaneous load rate $(\mathrm{Nm} / \mathrm{kg} / \mathrm{s})$ & 7.26 & $-16.71-31.23$ & 6.41 & $-22.13-34.95$ & -0.85 & $-19.01-17.32$ \\
\hline KAM impulse $(\mathrm{Nm} / \mathrm{kg} \cdot \mathrm{s})$ & 0.02 & $0.003-0.03$ & -0.002 & $-0.02-0.01$ & -0.02 & $-0.03--0.008$ \\
\hline
\end{tabular}

Note. Bold text $=$ significant difference

showed that peak Achilles tendon force was significantly larger in the no-orthotic condition ( $\mathrm{p}=.03$, $\mathrm{N}=9$ ) compared to the lateral orthosis (Figure 3a). A main effect $\left(\mathrm{p}<.05, \mathrm{p} \eta^{2}=0.39\right)$ was evident for Achilles tendon instantaneous load rate. Post-hoc analyses showed that Achilles tendon instantaneous load rate was significantly larger in the medial orthotic compared to the lateral $(\mathrm{p}=.003, \mathrm{~N}=11)$ and no-orthotic $(\mathrm{p}=.03, \mathrm{~N}=10)$ conditions. A main effect $\left(\mathrm{p}<.05, \mathrm{p} \eta^{2}=0.30\right)$ was shown for Achilles tendon impulse. Post-hoc analyses showed that Achilles tendon impulse was significantly larger in the no-orthotic $(\mathrm{p}=.004, \mathrm{~N}=11)$ condition compared to the lateral orthosis.

\section{Patellofemoral kinetics}

A main effect $\left(\mathrm{p}<.05, \mathrm{p}^{2}=0.29\right)$ was evident for the magnitude of peak patellofemoral force. Post-hoc pairwise comparisons showed that peak patellofemoral force was significantly larger in the medial condition compared to the lateral $(\mathrm{p}=.027$, $\mathrm{N}=9)$ and no-orthotic $(\mathrm{p}=.008, \mathrm{~N}=10)$ conditions (Figure 3b). In addition, a main effect $(\mathrm{p}<.05$, $\mathrm{p \eta}^{2}=0.26$ ) was found for peak patellofemoral stress. Post-hoc pairwise comparisons showed that peak patellofemoral force was significantly larger in the medial condition compared to the no-orthotic $(\mathrm{p}=.04, \mathrm{~N}=10)$ condition (Figure $3 \mathrm{c})$. A main effect $\left(\mathrm{p}<.05, \mathrm{p} \eta^{2}=0.51\right)$ was evident for the magnitude 
of patellofemoral instantaneous load rate. Posthoc pairwise comparisons showed that patellofemoral instantaneous load rate was significantly larger in the medial $(\mathrm{p}=.00001, \mathrm{~N}=11)$ and lateral $(\mathrm{p}=.03, \mathrm{~N}=9)$ orthotic conditions compared to the no-orthotic. Finally, a main effect $\left(\mathrm{p}<.05, \mathrm{p} \eta^{2}=0.25\right)$ was evident for the magnitude of patellofemoral impulse. Post-hoc pairwise comparisons showed that patellofemoral impulse was significantly larger in the medial orthotic in comparison to the lateral $(\mathrm{p}=.009, \mathrm{~N}=10)$ orthotic conditions.

\section{Knee kinetics}

A main effect $\left(\mathrm{p}<.05, \mathrm{p}^{2}=0.28\right)$ was evident for the magnitude of peak KAM. Post-hoc pairwise comparisons showed that peak KAM was significantly larger in the medial condition compared to the lateral $(p=0.03, N=9)$ orthosis (Figure $3 d)$. A main effect $\left(\mathrm{p}<0.05, \mathrm{p \eta}^{2}=0.39\right)$ was also evident for the magnitude of KAM impulse. Post-hoc pairwise comparisons showed that KAM impulse was significantly larger in the medial $(p=0.001, N=9)$ and no-orthotic $(\mathrm{p}=0.02, \mathrm{~N}=11)$ conditions in comparison to the lateral orthosis.

\section{Discussion and conclusion}

The aim of the current investigation was to examine the effects of orthoses with a $5^{\circ}$ medial and lateral wedge on the knee and ankle joint kinetics in female runners. This represents the first investigation to compare the effects of medially/laterally wedged orthoses on the patellofemoral, Achilles tendon and KAM loading parameters in female runners.

The current study importantly demonstrated that peak patellofemoral stress was significantly greater when running with medial orthoses compared to the no-orthoses condition. This observation specifically supports the findings of Almonroeder et al. (2015), who observed increases in patellofemoral loading when running using medial orthoses. Similar to the suggestion presented by Almonroeder et al. (2015) and Sinclair (2018), it is proposed that the increases in patellofemoral loading were mediated via an enhanced knee extension moment. The additional heel elevation provided by the orthotic conditions may have influenced the orientation of the ground reaction force vector such that the magnitude of the knee extensor moment, a key input parameter into the patellofemoral model, was enhanced. This observation may be important regarding the initiation of patellofemoral pain, as the initiation of symptoms is mediated through excessive patellofemoral joint stress (Farrokhi, et al., 2011). The findings from the current investigation indicate that running with medial orthoses may increase female runners' susceptibility to patellofemoral pain. This conclusion opposes those provided via previous randomized trials (Collins, et al., 2008) and the recent meta-analytic review by Bonanno et al. (2017), which designate that foot orthoses are effective in preventing injuries. Therefore, further mechanistic trials are required to better understand the biomechanical causes responsible for the improvements in patellofemoral symptoms mediated via orthotic intervention.

In addition, the peak KAM and the KAM impulse were significantly reduced in the lateral orthotic condition compared to the medial condition. This is in agreement with previous walking analyses described by Shimada et al. (2006); Hinman, Bowles, Payne, \& Bennell, (2008); Hinman, Bowles, \& Bennell, (2009); Jones, Zhang, Laxton, Findlow, \& Liu, (2013), who also reported reductions in the KAM when lateral orthoses were utilized. Furthermore, this observation agrees with the running observations of Lewinson et al., (2013) and Sinclair (2018), who showed that laterally wedged orthoses significantly reduced the peak KAM. It is proposed that this observation is caused by the configuration of the lateral orthoses, which reduce the moment arm of the ground reaction force vector about the knee joint centre. An interesting qualitative observation is that of an early peak in the KAM waveform, which is present only when running in the medial and lateral orthoses (Figure $3 d)$. It is proposed that this is a reflection of the increased stiffness of the orthoses, which are firmer than the typical running shoe insoles (Janakiraman, Shenoy \& Sandhu, 2011). This causes the rate at which the medial ground reaction force changes to increase, causing a discernible peak in the KAM curve in the orthotic conditions. Importantly, the $\mathrm{KAM}$ is an effective measure of medial compartment loading (Birmingham, et al., 2007), and both the peak KAM and KAM impulse are important predictors of knee OA (Kean, et al., 2012; Miyazaki, et al., 2002). Thus, it appears that the utilization of lateral orthoses may have potential to attenuate the risk of medial compartment knee OA in female runners.

The current investigation also revealed that the Achilles tendon loading parameters were significantly reduced in the lateral orthotic condition. As lateral orthoses would be expected to increase the ankle eversion angle, this observation lends further weight to recent findings which oppose the longstanding notion that hyper pronation augments the loads borne by the Achilles tendon. Indeed, in their prospective examination of 129 runners, Van Ginckel et al. (2009) found that lateral foot roll-over was a significant risk factor linked to the development of Achilles tendinopathy. As excessive tendon forces are the main stimulus for the initiation of Achilles tendinopathy (Abate, et al., 2009), this finding may also have clinical relevance, and indicates that lateral orthoses may have the potential to be efficacious for female runners susceptible to Achilles tendinopathy. 
A limitation in relation to the current investigation is that only the acute effects of wedged orthoses were examined in runners who did not habitually utilize foot orthoses. Therefore, although the lateral orthoses appear to attenuate tibiofemoral and Achilles tendon risk factors linked to the aetiology of chronic pathologies, it is currently unknown whether this will prevent or delay the initiation of injury symptoms. Furthermore, the duration over which the orthoses would need to be utilized in order to mediate a clinically meaningful change in patients is also not currently known. Although Hinman et al. (2008) found that the biomechanical effects of lateral orthoses do not appear to decline through continuous use, a longitudinal examination of these orthoses in runners would nonetheless be of practical and clinical relevance in the future. A further potential drawback is that only pain free controls were examined, meaning that only prophylactic inferences can be made in regard to the clinical efficacy of the orthoses examined in this study.
Based on the observations of the current study it is important that forthcoming clinical investigations seek to examine the efficacy of lateral foot orthoses in runners with existing tibiofemoral and Achilles tendon pathologies. Future developments of this nature will help to determine the efficacy of wedged orthoses as treatment modalities for runners with chronic pathologies.

The current study adds to the current literature in the field of clinical biomechanics by providing a comprehensive examination of the effects of medial and lateral orthoses on the knee and ankle loading parameters in female runners. The current investigation demonstrated that lateral orthoses reduced the magnitude of KAM and also the Achilles tendon force, but that medial orthoses increased patellofemoral loading. The results from this study indicate that lateral orthoses may be effective in attenuating risk of medial tibiofemoral OA and Achilles tendinopathy, but medial wedge orthoses may increase the risk of patellofemoral pain in female runners.

\section{References}

Abate, M., Silbernagel, K.G., Siljeholm, C., Di Iorio, A., De Amicis, D., Salini, V., \& Paganelli, R. (2009). Pathogenesis of tendinopathies: Inflammation or degeneration?. Arthritis Research and Therapy, 11(3), 235-241.

Almonroeder, T., Willson, J.D., \& Kernozek, T.W. (2013). The effect of foot strike pattern on Achilles tendon load during running. Annals of Biomedical Engineering, 41(8), 1758-1766.

Baker, K., Goggins, J., Xie, H., Szumowski, K., LaValley, M., Hunter, D.J., \& Felson, D.T. (2007). A randomized crossover trial of a wedged insole for treatment of knee osteoarthritis. Arthritis and Rheumatology, 56(4), 1198-1203.

Barrios, J.A., Butler, R.J., Crenshaw, J.R., Royer, T.D., \& Davis, I.S. (2013). Mechanical effectiveness of lateral foot wedging in medial knee osteoarthritis after 1 year of wear. Journal of Orthopaedic Research, 31(5), 659-664.

Barrios, J.A., \& Davis, I.S. (2010). The influence of lateral wedging over time in patients with medial knee osteoarthritis: An analysis of frontal plane knee mechanics and clinical outcomes. Journal of Orthopaedic and Sports Physical Therapy, 40(1), 25-26.

Bennell, K.L., Bowles, K.A., Payne, C., Cicuttini, F.M., Williamson, E., Forbes, A., \& Hinman, R.S. (2010). Effects of lateral wedge insoles on symptoms and structural disease progression in medial knee osteoarthritis: A 12-month randomised controlled trial. Osteoarthritis and Cartilage, 18, 11-12.

Besier, T.F., Draper, C.E., Gold, G.E., Beaupre, G.S., \& Delp, S.L. (2005). Patellofemoral joint contact area increases with knee flexion and weight-bearing. Journal of Orthopaedic Research, 23(2), 345-350.

Birmingham, T.B., Hunt, M.A., Jones, I.C., Jenkyn, T.R., \& Giffin, J.R. (2007). Test-retest reliability of the peak knee adduction moment during walking in patients with medial compartment knee osteoarthritis. Arthritis Care Research, 57(6), 1012-1017.

Boldt, A.R., Willson, J.D., Barrios, J.A., \& Kernozek, T.W. (2013). Effects of medially wedged foot orthoses on knee and hip joint running mechanics in females with and without patellofemoral pain syndrome. Journal of Applied Biomechanics, 29(1), 68-77.

Bonanno, D.R., Landorf, K.B., Munteanu, S.E., Murley, G.S., \& Menz, H.B. (2017). Effectiveness of foot orthoses and shock-absorbing insoles for the prevention of injury: A systematic review and meta-analysis. British Journal of Sports Medicine, 51(2), 86-96.

Cappozzo, A., Catani, F., Leardini, A., Benedeti, M.G., \& Della, C.U. (1995). Position and orientation in space of bones during movement: Anatomical frame definition and determination. Clinical Biomechanics, 10(4), 171-178.

Collins, N., Crossley, K., Beller, E., Darnell, R., McPoil, T., \& Vicenzino, B. (2008). Foot orthoses and physiotherapy in the treatment of patellofemoral pain syndrome: Randomised clinical trial. British Medical Journal, $337,1-8$.

Collins, N.J., Bierma-Zeinstra, S.M., Crossley, K.M., van Linschoten, R.L., Vicenzino, B., \& van Middelkoop, M. (2013). Prognostic factors for patellofemoral pain: A multicentre observational analysis. British Journal of Sports Medicine, 47(4), 227-233. 
Cook, J.L., \& Purdam, C.R. (2009). Is tendon pathology a continuum? A pathology model to explain the clinical presentation of load-induced tendinopathy. British Journal of Sports Medicine, 43(6), 409-416.

Crossley, K.M. (2014). Is patellofemoral osteoarthritis a common sequela of patellofemoral pain?. British Journal of Sports Medicine, 48(6), 409-410.

Crossley, K.M., Stefanik, J.J., Selfe, J., Collins, N.J., Davis, I.S., Powers, C.M., McConnell, J., Vicenzino, B., BazettJones, B.M., Esculier, J-F., Morrissey, D., \& Callaghan, M.J. (2016). Patellofemoral pain consensus statement from the 4th International Patellofemoral Pain Research Retreat, Manchester. Part 1: Terminology, definitions, clinical examination, natural history, patellofemoral osteoarthritis and patient-reported outcome measures. British Journal of Sports Medicine, 50(14), 839-843.

Farrokhi, S., Keyak, J.H., \& Powers, C.M. (2011). Individuals with patellofemoral pain exhibit greater patellofemoral joint stress: A finite element analysis study. Osteoarthritis and Cartilage, 19(3), 287-294.

Fukuchi, R.K., Fukuchi, C.A., \& Duarte, M. (2017). A public dataset of running biomechanics and the effects of running speed on lower extremity kinematics and kinetics. PeerJ, 5, e3298.

Graydon, R., Fewtrell, D., Atkins, S., \& Sinclair, J. (2015). The test-retest reliability of different ankle joint center location techniques. Foot and Ankle Online Journal, 8(11), 1-11.

Greenhalgh, G., \& Sinclair, J. (2014). Comparison of Achilles tendon loading between male and female recreational runners. Journal of Human Kinetics, 44(1), 155-159.

Hinman, R.S., Bowles, K.A., \& Bennell, K.L. (2009). Laterally wedged insoles in knee osteoarthritis: Do biomechanical effects decline after one month of wear?. BMC Musculoskeletal Disorders, 10(1), 146-151.

Hinman, R.S., Bowles, K.A., Payne, C., \& Bennell, K.L. (2008). Effect of length on laterally-wedged insoles in knee osteoarthritis. Arthritis Care Research, 59(1), 144-147.

Ho, K.Y., Blanchette, M.G., \& Powers, C.M. (2012). The influence of heel height on patellofemoral joint kinetics during walking. Gait and Posture, 36(2), 271-275.

Hreljac, A. (2004). Impact and overuse injuries in runners. Medicine and Science in Sports and Exercise, 36(5), 845-849.

Janakiraman, K., Shenoy, S., \& Sandhu, J.S. (2011). Firm insoles effectively reduce hemolysis in runners during long distance running - A comparative study. Sports Medicine, 3(1), 12-16.

Jones, R.K., Zhang, M., Laxton, P., Findlow, A.H., \& Liu, A. (2013). The biomechanical effects of a new design of lateral wedge insole on the knee and ankle during walking. Human Movement Science, 32(4), 596-604.

Kean, C.O., Hinman, R.S., Bowles, K.A., Cicuttini, F., Davies-Tuck, M., \& Bennell, K.L. (2012). Comparison of peak knee adduction moment and knee adduction moment impulse in distinguishing between severities of knee osteoarthritis. Clinical Biomechanics, 27(5), 520-523.

Kogler, G.F., Veer, F.B., Solomonidis, S.E., \& Paul, J.P. (1999). The influence of medial and lateral placement of orthotic wedges on loading of the plantar aponeurosis. An in vitro study. Journal of Bone and Joint Surgery, 81(10), 1403-1413.

Kutzner, I., Trepczynski, A., Heller, M.O., \& Bergmann, G. (2013). Knee adduction moment and medial contact force - Facts about their correlation during gait. PLoS One, 8(12), e81036.

Lewinson, R.T., Fukuchi, C.A., Worobets, J.T., \& Stefanyshyn, D.J. (2013). The effects of wedged footwear on lower limb frontal plane biomechanics during running. Clinical Journal of Sport Medicine, 23(3), 208-215.

Liu, X., \& Zhang, M. (2013). Redistribution of knee stress using laterally wedged insole intervention: Finite element analysis of knee-ankle-foot complex. Clinical Biomechanics, 28(1), 61-67.

Miyazaki, T., Wada, M., Kawahara, H., Sato, M., Baba, H., \& Shimada, S. (2002). Dynamic load at baseline can predict radiographic disease progression in medial compartment knee osteoarthritis. Annals of the Rheumatic Diseases, 61(7), 617-622.

Morgenroth, D.C., Medverd, J.R., Seyedali, M., \& Czerniecki, J.M. (2014). The relationship between knee joint loading rate during walking and degenerative changes on magnetic resonance imaging. Clinical Biomechanics, 29(6), 664-670.

Nigg, B.M., Stergiou, P., Cole, G., Stefanyshyn, D., Mündermann, A., \& Humble, N. (2003). Effect of shoe inserts on kinematics, center of pressure, and leg joint moments during running. Medicine and Science in Sports and Exercise, 35(2), 314-319.

Pham, T., Maillefert, J.F., Hudry, C., Kieffert, P., Bourgeois, P., Lechevalier, D., \& Dougados, M. (2004). Laterally elevated wedged insoles in the treatment of medial knee osteoarthritis: A two-year prospective randomized controlled study. Osteoarthritis and Cartilage, 12(1), 46-55.

Rafiaee, M., \& Karimi, M.T. (2012). The effects of various kinds of lateral wedge insoles on performance of individuals with knee joint osteoarthritis. International Journal of Preventative Medicine, 3(10), 693-698.

Rice, H., \& Patel, M. (2017). Manipulation of foot strike and footwear increases Achilles tendon loading during running. American Journal of Sports Medicine, 45(10), 2411-2417.

Rubin, R., \& Menz, H.B. (2005). Use of laterally wedged custom foot orthoses to reduce pain associated with medial knee osteoarthritis: A preliminary investigation. Journal of the American Podiatric Medical Association, 95(4), 347-352.

Self, B.P., \& Paine, D. (2001). Ankle biomechanics during four landing techniques. Medicine and Science in Sports and Exercise, 33(8), 1338-1344. 
Shimada, S., Kobayashi, S., Wada, M., Uchida, K., Sasaki, S., Kawahara, H., \& Baba, H. (2006). Effects of disease severity on response to lateral wedged shoe insole for medial compartment knee osteoarthritis. Archives of Physical Medicine and Rehabilitation, 87(11), 1436-1441.

Sinclair, J. (2018). Mechanical effects of medial and lateral wedged orthoses during running. Physical Therapy in Sport, 32, 48-53.

Sinclair, J., Hebron, J., \& Taylor, P.J. (2015). The test-retest reliability of knee joint center location techniques. Journal of Applied Biomechanics, 31(2), 117-121.

Sinclair, J., Isherwood, J., \& Taylor, P.J. (2014b). Effects of foot orthoses on Achilles tendon load in recreational runners. Clinical Biomechanics, 29(4), 956-958.

Sinclair, J., \& Selfe, J. (2015). Sex differences in knee loading in recreational runners. Journal of Biomechanics, 48(10), 2171-2175.

Sinclair, J., Taylor, P.J., Currigan, G., \& Hobbs, S.J. (2014a). The test-retest reliability of three different hip joint centre location techniques. Movement and Sport Sciences, 83, 31-39.

Starbuck, C., Price, C., Smith, L.C., \& Jones, R. (2017). The influence of an off the shelf lateral wedge orthotic on knee loading during running. Footwear Science, 9(1), 37-38.

Taunton, J.E., Ryan, M.B., Clement, D.B., McKenzie, D.C., Lloyd-Smith, D.R., \& Zumbo, B.D. (2002). A retrospective case-control analysis of 2002 running injuries. British Journal of Sports Medicine, 36(2), 95-101.

Thomas, M.J., Wood, L., Selfe, J., \& Peat, G. (2011). Anterior knee pain in younger adults as a precursor to subsequent patellofemoral osteoarthritis: A systematic review. BMC Musculoskeletal Disorders, 11, article 201(2010).

van Eijden, T.M., Kouwenhoven, E., Verburg, J., \& Weijs, W.A. (1998). A mathematical model of the patellofemoral joint. Journal of Biomechanics, 19(3), 219-229.

van Gent, B.R., Siem, D.D., van Middelkoop, M., van Os, T.A., Bierma-Zeinstra, S.S., \& Koes, B.B. (2007). Incidence and determinants of lower extremity running injuries in long distance runners: A systematic review. British Journal of Sports Medicine, 41(8), 469-480.

Van Ginckel, A., Thijs, Y., Hesar, N.G.Z., Mahieu, N., De Clercq, D., Roosen, P., \& Witvrouw, E. (2009). Intrinsic gait-related risk factors for Achilles tendinopathy in novice runners: A prospective study. Gait and Posture, 29(3), 387-391.

Ward, S.R., \& Powers, C.M. (2014). The influence of patella alta on patellofemoral joint stress during normal and fast walking. Clinical Biomechanics, 19(10), 1040-1047.

Waryasz, G.R., \& McDermott, A.Y. (2008). Patellofemoral pain syndrome (PFPS): A systematic review of anatomy and potential risk factors. Dynamic Medicine, 7(1), 9-13.

Wise, B.L., Niu, J., Yang, M., Lane, N.E., Harvey, W., Felson, D.T., \& Lewis, C.E. (2012). Patterns of compartment involvement in tibiofemoral osteoarthritis in men and women and in whites and African Americans. Arthritis Care Research, 64(6), 847-852.

Zhao, D., Banks, S.A., Mitchell, K.H., D’Lima, D.D., Colwell, C.W., \& Fregly, B.J. (2007). Correlation between the knee adduction torque and medial contact force for a variety of gait patterns. Journal of Orthopaedic Research, 25(6), 789-797.

Submitted: July 1,2017

Accepted: July, 10, 2018

Published Online First: November 11, 2019
Correspondence to:

Jonathan Sinclair, Ph.D.

Faculty of Health \& Wellbeing

Darwin Building, DB217

University of Central Lancashire, Preston, Lancashire, UK

Phone: +44 (0) 1772892796

E-mail: jksinclair@uclan.ac.uk

\section{Competing interests}

No conflict of interest will arise from any of the authors involved in this paper.

\section{Author contributions}

All named authors have made a significant and substantial contribution to all aspects of the study. Each of the named authors provided a meaningful contribution to the conception, design, execution and interpretation of the study data in addition to writing, drafting and revising the paper itself. This paper is submitted with the agreement and approval of both authors.

\section{Funding}

No external funding was provided for this paper.

\section{Acknowledgements}

The authors wish to thank Gareth Shadwell for his technical assistance during data collection. 